\title{
COVID-19 infection in adult patients with hematological malignancies: a European Hematology Association Survey (EPICOVIDEHA)
}

Livio Pagano ${ }^{1,2^{*}+} \oplus$, Jon Salmanton-García ${ }^{3,4+} \oplus$, Francesco Marchesi ${ }^{5} \oplus$, Alessandro Busca ${ }^{6}$,

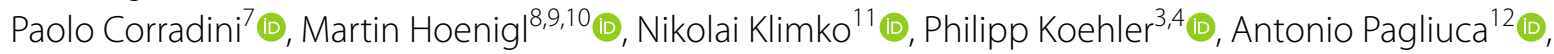

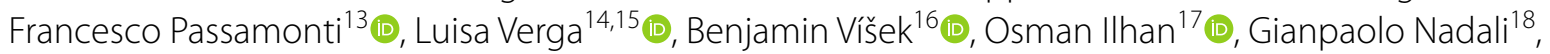
Barbora Weinbergerová ${ }^{19}$, Raúl Córdoba-Mascuñano ${ }^{20}{ }^{(0)}$, Monia Marchetti ${ }^{21}$ (D), Graham P. Collins 22 ,

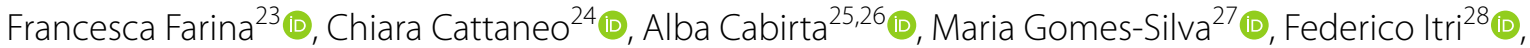

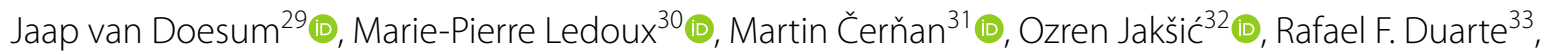
Gabriele Magliano ${ }^{34}$ D , Ali S. Omrani ${ }^{35}$ D , Nicola S. Fracchiolla ${ }^{36}$ (D) Austin Kulasekararaj ${ }^{37,38}$ (D),

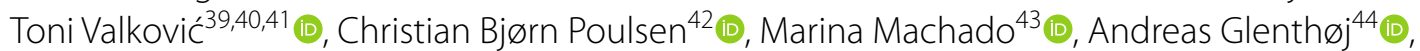

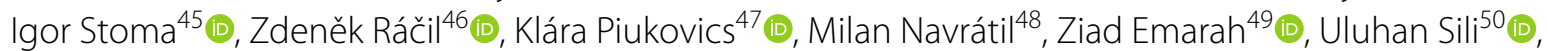

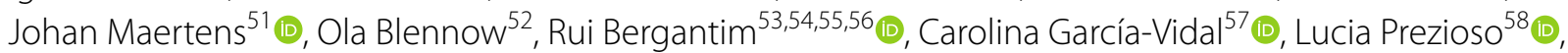

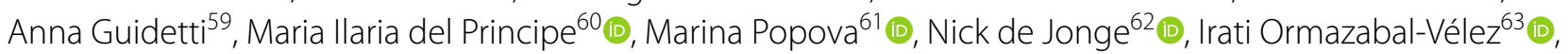
Noemí Fernández ${ }^{64}$, Iker Falces-Romero ${ }^{65}$ (D) Annarosa Cuccaro ${ }^{66}$ (1) Stef Meers ${ }^{67}$ (D),

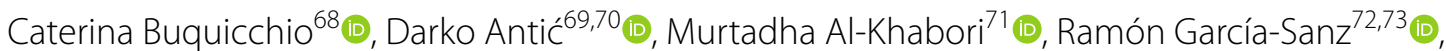

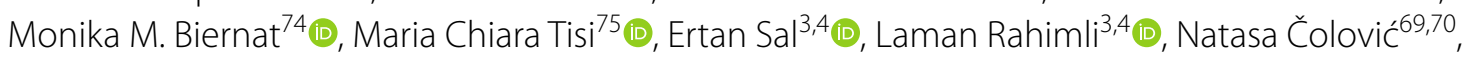

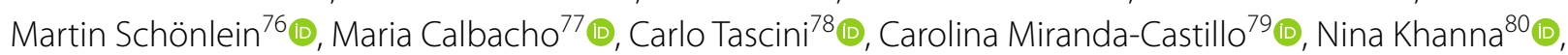

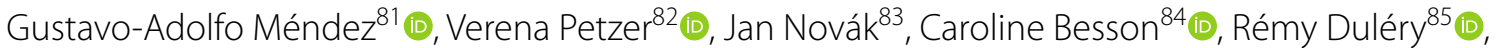

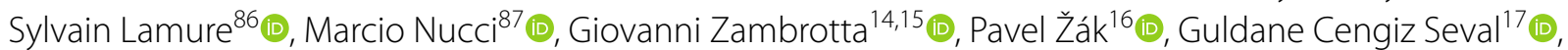

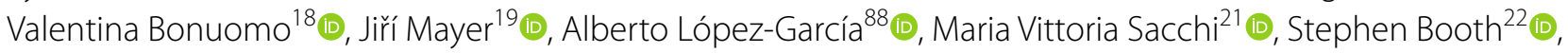
Fabio Ciceri ${ }^{23}$ (D), Margherita Oberti ${ }^{24}$, Marco Salvini ${ }^{13}$, Macarena Izuzquiza ${ }^{25,26}$, Raquel Nunes-Rodrigues ${ }^{27}$ (D),

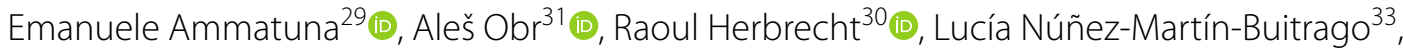
Valentina Mancini $i^{34}$, Hawraa Shwaylia ${ }^{89}$, Mariarita Sciumè ${ }^{36} \mathbb{D}_{\text {, Jenna }}$ Essame $^{37} \mathbb{B}$, Marietta Nygaard ${ }^{42}$, Josip Batinić ${ }^{40,90,91}$ (D), Yung Gonzaga ${ }^{92}$ (D), Isabel Regalado-Artamendi ${ }^{93}$ (D), Linda Katharina Karlsson ${ }^{44}$ (D), Maryia Shapetska ${ }^{94}$ (D, Michaela Hanakova ${ }^{46}$, Shaimaa El-Ashwah ${ }^{49}$ (D) Zita Borbényi ${ }^{47}$, Gökçe Melis Çolak ${ }^{50}{ }^{(0)}$, Anna Nordlander ${ }^{52,95}$, Giulia Dragonetti ${ }^{1,2}$ (D), Alessio Maria Edoardo Maraglino ${ }^{1,2}$, Amelia Rinaldi ${ }^{58}$ (D), Cristina De Ramón-Sánchez ${ }^{96}$ [D and Oliver A. Cornely $3,97,98,99,100$ (B) on behalf of EPICOVIDEHA working group

*Correspondence: Livio.Pagano@unicatt.it

†Livio Pagano and Jon Salmanton-García have contributed equally to this

work

${ }^{1}$ Hematology, Fondazione Policlinico Universitario Agostino Gemelli -

IRCCS - Università Cattolica del Sacro Cuore, Rome, Italy

Full list of author information is available at the end of the article

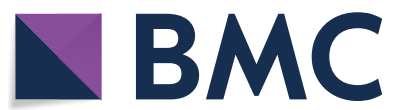

(c) The Author(s) 2021. Open Access This article is licensed under a Creative Commons Attribution 4.0 International License, which permits use, sharing, adaptation, distribution and reproduction in any medium or format, as long as you give appropriate credit to the original author(s) and the source, provide a link to the Creative Commons licence, and indicate if changes were made. The images or other third party material in this article are included in the article's Creative Commons licence, unless indicated otherwise in a credit line to the material. If material is not included in the article's Creative Commons licence and your intended use is not permitted by statutory regulation or exceeds the permitted use, you will need to obtain permission directly from the copyright holder. To view a copy of this licence, visit http://creativecommons.org/licenses/by/4.0/. The Creative Commons Public Domain Dedication waiver (http://creativeco mmons.org/publicdomain/zero/1.0/) applies to the data made available in this article, unless otherwise stated in a credit line to the data. 


\begin{abstract}
Background: Patients with hematological malignancies $(\mathrm{HM})$ are at high risk of mortality from SARS-CoV-2 disease 2019 (COVID-19). A better understanding of risk factors for adverse outcomes may improve clinical management in these patients. We therefore studied baseline characteristics of HM patients developing COVID-19 and analyzed predictors of mortality.
\end{abstract}

Methods: The survey was supported by the Scientific Working Group Infection in Hematology of the European Hematology Association (EHA). Eligible for the analysis were adult patients with HM and laboratory-confirmed COVID19 observed between March and December 2020.

Results: The study sample includes 3801 cases, represented by lymphoproliferative (mainly non-Hodgkin lymphoma $n=1084$, myeloma $n=684$ and chronic lymphoid leukemia $n=474$ ) and myeloproliferative malignancies (mainly acute myeloid leukemia $n=497$ and myelodysplastic syndromes $n=279$ ). Severe/critical COVID-19 was observed in $63.8 \%$ of patients ( $n=2425)$. Overall, 2778 (73.1\%) of the patients were hospitalized, 689 (18.1\%) of whom were admitted to intensive care units (ICUs). Overall, 1185 patients (31.2\%) died. The primary cause of death was COVID19 in 688 patients (58.1\%), HM in 173 patients (14.6\%), and a combination of both COVID-19 and progressing HM in 155 patients (13.1\%). Highest mortality was observed in acute myeloid leukemia (199/497, 40\%) and myelodysplastic syndromes (118/279, 42.3\%). The mortality rate significantly decreased between the first COVID-19 wave (March-May $2020)$ and the second wave (October-December 2020) (581/1427, 40.7\% vs. 439/1773, 24.8\%, $p$ value <0.0001). In the multivariable analysis, age, active malignancy, chronic cardiac disease, liver disease, renal impairment, smoking history, and ICU stay correlated with mortality. Acute myeloid leukemia was a higher mortality risk than lymphoproliferative diseases.

Conclusions: This survey confirms that COVID-19 patients with HM are at high risk of lethal complications. However, improved COVID-19 prevention has reduced mortality despite an increase in the number of reported cases.

Keywords: COVID-19, Pandemic, Hematological malignancies, Epidemiology, EHA

\section{Background}

Coronavirus disease 19 (COVID-19), caused by severe acute respiratory syndrome coronavirus 2 (SARS-CoV-2) was declared a pandemic by the World Health Organization (WHO) in March 2020 [1]. During that year, COVID-19 spread worldwide, causing over 1.5 million deaths. Patients with hematological malignancies (HM) are considered at high risk of developing severe and lifethreatening infections, because of immune deficiency and immunosuppressive treatments. Severe infections in HM patients can determine a worsening of the clinical outcome, potentially affecting life expectancy. SARSCoV-2 affects $\mathrm{HM}$ patients disproportionally, leading often to severe COVID-19 with a high mortality rate [2]. So far, various reports have been published on COVID$19 \mathrm{HM}$ patients, but in most cases on small patient cohorts [3-8], specific HM [9-12], or larger reports from single countries [13-16]. In June 2021, an ongoing worldwide registry of the American Society of Hematology (ASH) reported a total of 1013 cases of COVID-19 infections in HM [17]. Altogether, these data show a significant mortality rate, ranging between 13.8 and $39 \%$, and highlighting the major relevance of COVID-19 management in this frail patient population [3-17]. Advanced disease, one or more co-morbidities, older age, type of malignancy, in particular acute myeloid leukemia (AML), and several laboratory parameters, for example high C-reactive protein, lymphopenia, and neutropenia, were found to be risk factors for COVID-19 in HM patients [14-16]. A possible role of some antineoplastic drugs has been reported to be protective in patients with myeloproliferative disorders $[18,19]$. Despite the current spread of vaccination programs among HM patients in several countries, the future trajectory of this pandemic seems still to be uncertain. Collecting further data and gaining a better knowledge about COVID-19 in HM is therefore relevant for hematologists around the world.

The EPICOVIDEHA, Epidemiology of COVID-19 Infection in Patients with Hematological Malignancies: A European Hematology Association Survey, multinational project aimed to collect COVID-19 cases occurring in HM patients in 2020, and was performed on behalf of the Scientific Working Group Infection in Hematology of the European Hematology Association (EHA). The objective was to assess epidemiology and outcomes of COVID-19 in HM patients.

\section{Methods}

\section{Study design and patients}

EPICOVIDEHA is an international open web-based registry for patients with HM infected with SARS-CoV-2 
[20]. The survey has been approved by the Institutional Review Board and Ethics Committee of the Fondazione Policlinico Universitario Agostino Gemelli-IRCCS, Università Cattolica del Sacro Cuore of Rome, Italy (Study ID: 3226). The corresponding local ethics committee of each participating institution has approved the EPICOVIDEHA study when applicable. EPICOVIDEHA has been registered at www.clinicaltrials.gov with the identifier NCT04733729. Different medical hematology societies have joined this project (Additional file 1: Table 1). Participating institutions documented episodes of COVID-19 in their patients with baseline HM between March 2020 and December 2020. Data were collected via the EPICOVIDEHA electronic case report form (eCRF), available at www.clinicalsurveys.net. This online survey is provided by EFS Fall 2018 (Questback, Cologne, Germany).

\section{Procedures}

Experts at the University Hospital Cologne, Cologne, Germany, with previous experience in the research and study of HM and infectious diseases, reviewed each case included in the registry, for completeness and consistency. Each patient was reviewed for validity following the inclusion criteria: (a) HM (excluding non-malignant hematological disorders or solid tumors), (b) malignancy with activity during the 5 years before COVID-19 (either diagnosis or treatment), (c) patient over 18 years of age, (d) hematological diagnosis before COVID-19, and (e) laboratory diagnosis for COVID-19 (not clinical diagnosis). Data on patients' demographic characteristics and baseline conditions before COVID-19 were collected. Additional variables, such as type of COVID-19 test, the reason for COVID-19 test, admission to ICU after COVID-19, day of death, and cause of death were collected.

The diagnosis of COVID-19 was made according to the international recommendations of the WHO [21]. At the time of the survey design, no well-defined criteria were yet available to establish a degree of infection severity. Therefore, the following definitions have been included: asymptomatic (no clinical signs or symptoms); mild (non-pneumonia and mild pneumonia); severe (dyspnea, respiratory frequency $\geq 30$ breaths per min, $\mathrm{SpO} 2 \leq 93 \%, \mathrm{PaO}_{2} / \mathrm{FiO}_{2}<300$, or lung infiltrates $>50 \%$ ), and critical (patients admitted in intensive care for respiratory failure, septic shock, or multiple organ dysfunction or failure). However, our grading definition was very similar to the one suggested by the China Centers for Disease Control and Prevention definitions [22]. Overall case-fatality rate (overall mortality) was define as the proportion of deaths for any cause compared to the total number of patients registered during the observation time. Attributable or contributable deaths were defined on the basis of subjective judgment of the local physician.

\section{Study objectives}

The primary objective of this study was to assess the epidemiology and the outcome of HM affected by COVID19. Secondary objectives were: (1) to estimate the prevalence of disease severity (i.e., asymptomatic, mild, severe disease); (2) to evaluate the prevalence of ICU admission; (3) to estimate the frequency of pre-existing co-morbidities; (4) to evaluate the overall case-fatality rate; (5) to assess geographical patterns of the disease; (6) to stratify patients according to treatment of the underlying HM (off/on) and according to type of therapy (i.e., chemotherapy, immunotherapy, targeted therapy, hematopoietic stem cell transplant [HSCT]).

\section{Statistical analysis}

The primary analysis describes the demographic and clinical characteristics of patients with COVID-19 after a previous HM diagnosis. Categorical variables are presented with frequencies and percentages, and continuous variables with median, interquartile range (IQR) and absolute range. The secondary analysis studies independent predictors of overall mortality in hematological patients with COVID-19, by employing a Cox proportional hazard model. Univariable Cox regression model was performed with variables suspected to play a role in the mortality of HM patients with COVID-19 (i.e. sex [reference female], age, malignancy status [reference controlled disease], hematological malignancy [reference Hodgkin lymphoma], COVID-19 infection [reference asymptomatic], ICU stay, chronic cardiopathy, liver disease, chronic pulmonary disease, diabetes mellitus, obesity, renal impairment, smoking history, neutrophils [reference $\leq 500$ units $/ \mathrm{mm}^{3}$ ], lymphocytes [reference $\leq 200$ units $/ \mathrm{mm}^{3}$ ], and last chemotherapy [reference $>3$ months before COVID-19]). Variables with a $p$-value $\leq 0.1$ were considered for multivariable analysis. A multivariable Cox regression model was calculated with the Wald backward method, and only those variables that were statistically significant displayed. Mortality was analyzed using Kaplan-Meier survival plots. Log-rank test was used to compare the survival probability of the patients included in the different models, based on COVID-19 severity, baseline malignancy, pandemic wave, and HSCT/non-HSCT. A p-value $\leq 0.05$ was considered statistically significant. No a priori sample size calculation was done for this exploratory study. SPSSv25.0 was employed for statistical analyses (SPSS, IBM Corp., Chicago, IL, United States). 


\section{Role of funding source}

The funder of the study had no role in study design, data analysis, and interpretation, or writing of the report. All authors had full access to the data and had final responsibility for the decision to submit for publication.

\section{Results}

A total of 132 centers in 32 countries participated in this survey (Fig. 1, Additional file 2: Tables 2), and registered 4117 cases. Of these, 316 (7.7\%) were excluded for the following reasons: age $<18$ years old, clinical diagnosis of COVID-19, double-entry, non-malignant hematological diseases, incomplete information, more than 5 years offtherapy from the last chemotherapy, or solid cancer.

The demographic and clinical characteristics of 3801 valid cases are reported in Table 1 . There was a higher prevalence of males $(n=2222,58.5 \%)$ and Caucasian ethnic background $(n=3289,86.5 \%)$. The median age was 65 years (IQR: 54-74; range 18-95).

Patients with non-Hodgkin lymphoma (NHL) represented the largest subgroup $(n=1084,28.5 \%)$, followed by patients with multiple myeloma (MM) $(n=684,18 \%)$ and those with AML $(n=497,13.1 \%)$. Overall, $67.3 \%$ of the patients who developed COVID-19 had a baseline lymphoproliferative disease $(n=2557)$ (Table 1$)$. More than $51 \%$ of the patients had active disease $(n=1963)$, and 2502 patients $(65.8 \%)$ had received chemotherapy in the 3 months before the onset of COVID-19 (Table 2). The most frequent treatments were chemotherapy with immunotherapy or immunotherapy alone administered to 983 patients $(25.9 \%)$, compatible with the proportion of patients with NHL. In 271 patients (7.1\%), the infection occurred concomitantly with the diagnosis of HM, and in 138 of those $(50.9 \%)$ before treatment initiation for the baseline malignancy (Table 1). Five hundred fiftyseven patients $(14.7 \%)$ had a transplant procedure performed in their clinical history (292 autologous HSCT [auto-HSCT] and 265 allogeneic HSCT [allo-HSCT]). In 247 patients, 173 allo-HSCT and 74 auto-HSCT recipients, the transplant procedure was the last therapy before COVID-19 infection. In total 24 patients in the registry were treated with chimeric antigen receptor $\mathrm{T}$ (CAR$\mathrm{T}$ ) cells reinfusion, of which 3 patients had been treated with additional therapies after the CAR-T cell therapy (Table 2).

Overall, 2304 (60.6\%) patients had at least one comorbidity, with cardiovascular diseases being most frequent $(n=1146,30.1 \%)$. In 447 patients (12.5\%) smoking history was reported (Table 1 ).

At the onset of COVID-19 infection, 280 patients (7.4\%) had neutrophils below $0.5 \times 10^{9} / \mathrm{mm}^{3}$, and 344 patients (9.1\%) lymphocytes below $0.2 \times 10^{9} / \mathrm{mm}^{3}$ (Table 3).

SARS-CoV-2 infection was diagnosed by nasopharyngeal swab in almost all patients $(n=3700$, 97.3\%). COVID-19 tests were performed in 3027 patients (79.6\%) because of pulmonary and/or extrapulmonary symptoms, and in 727 patients $(19.1 \%)$ as part of asymptomatic screening. Reason for testing was unknown in 47 (1.2\%). Presence of respiratory symptoms, mainly cough and dyspnea, was the most frequent clinical presentation, reported in 2285 (60.1\%), and in 831 of them $(21.9 \%)$ it was combined with extrapulmonary symptoms. In 742 patients (19.5\%) extrapulmonary symptoms, in particular anosmia, diarrhea,

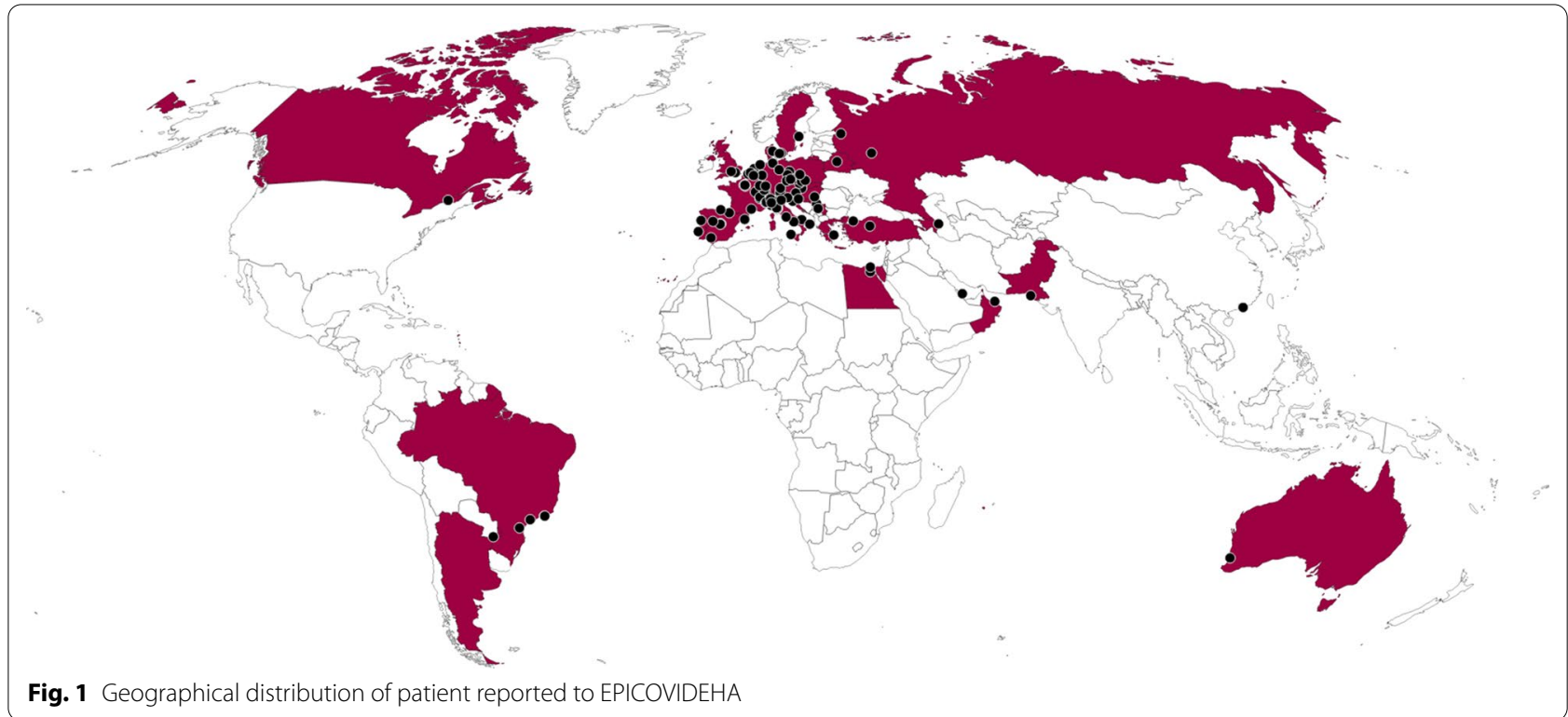


Table 1 Demographic and clinical characteristics of enrolled patients at COVID-19 diagnosis

\begin{tabular}{|c|c|c|}
\hline & $n$ & $\%$ \\
\hline \multicolumn{3}{|l|}{ Sex } \\
\hline Female & 1579 & 41.5 \\
\hline Male & 2222 & 58.5 \\
\hline Age, median (IQR) [range] & \multicolumn{2}{|c|}{65 (54-74), [18-95] } \\
\hline \multicolumn{3}{|l|}{ Comorbidities } \\
\hline Chronic cardiopathy & 1146 & 30.1 \\
\hline Chronic pulmonary disease & 614 & 16.2 \\
\hline Diabetes mellitus & 620 & 16.3 \\
\hline Liver disease & 167 & 4.4 \\
\hline Obesity & 345 & 9.1 \\
\hline Renal impairment & 325 & 8.6 \\
\hline Smoking history & 477 & 12.5 \\
\hline No risk factor identified & 1463 & 38.5 \\
\hline \multicolumn{3}{|c|}{ Baseline hematological malignancies } \\
\hline Acute lymphoid leukemia & 169 & 4.4 \\
\hline Chronic lymphoid leukemia & 474 & 12.5 \\
\hline Acute myeloid leukemia & 497 & 13.1 \\
\hline Chronic myeloid leukemia & 161 & 4.2 \\
\hline Myelodysplastic syndrome & 279 & 7.3 \\
\hline Low-intermediate risk & 138 & 3.6 \\
\hline High risk & 48 & 1.3 \\
\hline Not stated & 93 & 2.4 \\
\hline Hairy cell leukemia & 23 & 0.6 \\
\hline Hodgkin lymphoma & 135 & 3.6 \\
\hline Non-Hodgkin lymphoma & 1084 & 28.5 \\
\hline Indolent & 497 & 13.1 \\
\hline Aggressive & 516 & 13.6 \\
\hline Not stated & 71 & 1.9 \\
\hline Essential thrombocythemia & 69 & 1.8 \\
\hline Myelofibrosis & 122 & 3.2 \\
\hline Polycythemia vera & 70 & 1.8 \\
\hline Systemic mastocytosis & 6 & 0.2 \\
\hline Multiple myeloma & 684 & 18.0 \\
\hline Amyloidosis & 8 & 0.2 \\
\hline Aplastic anemia & 20 & 0.5 \\
\hline \multicolumn{3}{|l|}{ Status $^{a}$} \\
\hline Controlled disease & 1760 & 46.3 \\
\hline Complete remission & 1170 & 30.8 \\
\hline Partial remission & 590 & 15.5 \\
\hline Activedisease & 1963 & 51.6 \\
\hline Onset & 888 & 23.4 \\
\hline Refractory/Resistant & 473 & 12.4 \\
\hline Stable disease & 524 & 13.8 \\
\hline Unknown & 78 & 2.1 \\
\hline Unknown & 78 & 2.1 \\
\hline
\end{tabular}

Data can be super additive

a Onset patients had a contemporaneous diagnosis of the malignancy and the COVID-19, regardless of malignancy treatment initiation. Stable disease patients include patients at watch and wait
Table 2 Summary of received treatments for Hematological Malignancies at the onset of COVID-19

\begin{tabular}{|c|c|c|}
\hline & $n$ & $\%$ \\
\hline \multicolumn{3}{|c|}{ Last/ongoing treatment strategy before COVID-19 } \\
\hline Immunochemotherapy & 857 & 22.5 \\
\hline Targeted therapy ${ }^{\mathrm{a}}$ & 607 & 16.0 \\
\hline Conventional chemotherapy & 597 & 15.7 \\
\hline No treatment & 538 & 14.1 \\
\hline Palliative/supportive measures & 226 & 6.0 \\
\hline Immunomodulators & 218 & 5.7 \\
\hline Allogeneic HSCT & 173 & 4.6 \\
\hline Anagrelide/Hydroxyurea & 145 & 3.8 \\
\hline Hypomethylating agents & 141 & 3.7 \\
\hline Immunotherapy only & 125 & 3.3 \\
\hline Autologous HSCT & 74 & 1.9 \\
\hline Unknown & 41 & 1.1 \\
\hline Other & 28 & 0.7 \\
\hline CAR-T & 21 & 0.6 \\
\hline Radiotherapy & 10 & 0.3 \\
\hline \multicolumn{3}{|l|}{ Summary of received treatment ${ }^{b}$} \\
\hline Chemotherapy & 3178 & 83.6 \\
\hline In the last month & 1979 & 52.1 \\
\hline In the last 3 months & 523 & 13.8 \\
\hline Treatment ended $>3$ months & 631 & 16.6 \\
\hline Not stated & 45 & 1.2 \\
\hline Radiotherapy & 186 & 4.9 \\
\hline Allogeneic HSCT & 265 & 7.0 \\
\hline Autologous HSCT & 292 & 7.7 \\
\hline CAR-T & 24 & 0.6 \\
\hline Other strategies & 150 & 3.9 \\
\hline No treatment & 538 & 14.2 \\
\hline
\end{tabular}

HSCT Hematopoietic stem cell transplantation, CAR-T chimeric antigen receptor T-cell therapies

a Bortezomib, ibrutinib, idelalisib, ruxolitinib, TKI (tyrosine kinase inhibitors), and venetoclax

${ }^{\mathrm{b}}$ Data can be super-additive

skin rash, were predominant in terms of clinical presentation (Table 3).

COVID-19 infection was determined to be critical in 689 patients (18.1\%), severe in $1736(45.7 \%)$, mild in 658 $(17.3 \%)$, and asymptomatic in $675(17.8 \%)$ (Table 3$)$.

Overall, 2778 patients $(73.1 \%)$ were hospitalized. The median duration of overall hospitalization was 15 days (IQR: 8-27, range 1-235), regardless of patient outcome. Among the hospitalized patients, 689 (18.1\%) required hospitalization in an ICU, 449 of these (65.2\%) with invasive mechanical ventilation (MV) (Table 3).

Altogether, during the observation phase, 1185 patients (31.2\%) died. The primary cause of death was COVID-19 in 688 patients (58.1\%), HM in 173 patients (14.6\%), and 
Table 3 Clinical features of COVID-19 in our patient cohort

\begin{tabular}{|c|c|c|}
\hline & $n$ & $\%$ \\
\hline \multicolumn{3}{|l|}{ COVID-19infection } \\
\hline Asymptomatic & 675 & 17.8 \\
\hline Mild & 658 & 17.3 \\
\hline Severe & 1736 & 45.7 \\
\hline Critical & 689 & 18.1 \\
\hline Unknown & 43 & 1.1 \\
\hline \multicolumn{3}{|l|}{ COVID-19 test sample } \\
\hline BAL & 60 & 1.6 \\
\hline SARS-CoV-2 nasopharyngeal swab & 3700 & 97.3 \\
\hline SARS-CoV-2 serology & 86 & 2.3 \\
\hline \multicolumn{3}{|l|}{ Reason for COVID-19 test $^{\mathrm{a}}$} \\
\hline Pulmonary symptoms & 1454 & 38.3 \\
\hline Pulmonary + extrapulmonary symptoms & 831 & 21.9 \\
\hline Extrapulmonary symptoms & 742 & 19.5 \\
\hline Screening & 727 & 19.1 \\
\hline Unknown & 47 & 1.2 \\
\hline \multicolumn{3}{|l|}{ Neutrophils level at COVID-19 diagnosis ${ }^{\mathrm{b}}$} \\
\hline$\leq 0.5 \times 10^{9} / \mathrm{mm}^{3}$ & 280 & 7.4 \\
\hline $0.501-0.999 \times 10^{9} / \mathrm{mm}^{3}$ & 217 & 5.7 \\
\hline$\geq 1 \times 10^{9} / \mathrm{mm}^{3}$ & 2738 & 72.0 \\
\hline \multicolumn{3}{|l|}{ Lymphocytes level at COVID-19 diagnosis ${ }^{b}$} \\
\hline$\leq 0.2 \times 10^{9} / \mathrm{mm}^{3}$ & 344 & 9.1 \\
\hline $0.201-0.499 \times 10^{9} / \mathrm{mm}^{3}$ & 538 & 14.2 \\
\hline$\geq 0.5 \times 10^{9} / \mathrm{mm}^{3}$ & 2367 & 62.3 \\
\hline \multicolumn{3}{|l|}{ Stay during COVID-19 } \\
\hline Admitted to hospital & 2778 & 73.1 \\
\hline Length of hospital stay, median (IQR) [range] & 15 (8-27), [1-235] & - \\
\hline ICU & 689 & 18.1 \\
\hline Length of ICU stay, median (IQR) [range] & $11(5-20),[1-111]$ & - \\
\hline Invasive MV & 449 & 11.8 \\
\hline Non-invasive MV & 221 & 5.8 \\
\hline \multicolumn{3}{|l|}{ Clinical outcome of COVID-19 } \\
\hline Death & 1185 & 31.2 \\
\hline Observation time, median (IQR) [range] & $89(21-172),[0-436]$ & - \\
\hline \multicolumn{3}{|l|}{ Reason for death ${ }^{\mathrm{a}}$} \\
\hline Not related to COVID-19 & 125 & 3.3 \\
\hline Contributable by COVID-19 & 155 & 4.1 \\
\hline Attributable to COVID-19 & 843 & 22.2 \\
\hline Attributable to HM & 328 & 8.6 \\
\hline Death due to other reasons & 123 & 3.2 \\
\hline Death due to unknown reasons & 78 & 2.1 \\
\hline
\end{tabular}

BAL Bronchoalveolar lavage, COVID-19coronavirus disease 19, HM hematological malignancy, ICU intensive care unit, MV mechanical ventilation, SARS-CoV-2 severe acute respiratory syndrome coronavirus 2

${ }^{\text {a }}$ Data can be super additive

${ }^{\mathrm{b}}$ Data not available in all patients

a combination of both COVID-19 and progressing HM in 155 patients (13.1\%). In the remaining cases the cause was unknown or due to other reasons.
Patients over the age of 70 years had the highest mortality $(661 / 1475,44.8 \%)$. Considering the different HM, the higher number of fatalities was observed in AML (199/497, 40\%) and in myelodysplastic syndromes (MDS) 
Table 4 Overall mortality rate by disease and treatment received

\begin{tabular}{|c|c|c|}
\hline & \multicolumn{2}{|c|}{ Overall mortality } \\
\hline & Survived $n(\%)$ & Died $n(\%)$ \\
\hline \multicolumn{3}{|c|}{ Baseline hematological malignancies } \\
\hline Acute lymphoid leukemia & $125(74)$ & $44(26)$ \\
\hline Chronic lymphoid leukemia & $340(71.7)$ & $134(28.3)$ \\
\hline Acute myeloid leukemia & $298(60)$ & $199(40)$ \\
\hline Chronic myeloid leukemia & $144(89.5)$ & $17(10.5)$ \\
\hline Myelodysplastic syndrome & $161(57.7)$ & $118(42.3)$ \\
\hline Low-intermediate risk & $77(55.8)$ & $61(44.2)$ \\
\hline High risk & $26(54.2)$ & $22(45.8)$ \\
\hline Not stated & $58(62.4)$ & $35(37.6)$ \\
\hline Hairy cell leukemia & $15(65.2)$ & $8(34.8)$ \\
\hline Hodgkin lymphoma & $120(88.9)$ & $15(11.1)$ \\
\hline Non-Hodgkin lymphoma & $739(68.2)$ & $345(31.8)$ \\
\hline Indolent & $354(71.3)$ & $143(28.7)$ \\
\hline Aggressive & $337(65.3)$ & $179(34.7)$ \\
\hline Not stated & $48(67.6)$ & $23(32.4)$ \\
\hline Essential thrombocythemia & $57(82.6)$ & $12(17.4)$ \\
\hline Myelofibrosis & $77(63.1)$ & $45(36.9)$ \\
\hline Polycythemia vera & $56(80)$ & $14(20)$ \\
\hline Systemic mastocytosis & $5(83.4)$ & $1(16.6)$ \\
\hline Multiple Myeloma & $458(67)$ & $226(33)$ \\
\hline Amyloidosis & $7(87.5)$ & $1(12.5)$ \\
\hline Aplastic anemia & $14(70)$ & $6(30)$ \\
\hline \multicolumn{3}{|c|}{ Last/ongoing treatment strategy before COVID-19 } \\
\hline Anagrelide/Hydroxyurea & $106(73.1)$ & $39(26.9)$ \\
\hline Conventional chemotherapy & $423(70.9)$ & $174(29.1)$ \\
\hline Hypomethylating agents & $58(41.2)$ & $83(58.8)$ \\
\hline Immunotherapy only & $89(71.2)$ & $36(28.8)$ \\
\hline Immunochemotherapy & $595(69.4)$ & $262(30.6)$ \\
\hline Immunomodulators & $139(63.8)$ & $79(36.2)$ \\
\hline Targeted therapy ${ }^{a}$ & $453(74.6)$ & $154(25.4)$ \\
\hline Allogeneic HSCT & $130(75.2)$ & $43(24.8)$ \\
\hline Autologous HSCT & $54(73)$ & $20(27)$ \\
\hline CAR-T & $11(52.4)$ & $10(47.6)$ \\
\hline Radiotherapy & $9(90)$ & $1(10)$ \\
\hline Palliative/supportive measures & 122(56) & $104(46)$ \\
\hline Other & $17(60.7)$ & $11(39.3)$ \\
\hline Unknown & $28(68.3)$ & $13(31.7)$ \\
\hline No treatment & $382(71)$ & $156(29)$ \\
\hline
\end{tabular}

HSCT Hematopoietic stem cell transplantation, CAR-T chimeric antigen receptor T-cell therapies

${ }^{a}$ Bortezomib, ibrutinib, idelalisib, ruxolitinib, TKI (tyrosine kinase inhibitors) and venetoclax

(118/279, 42.3\%) (Table 4). Mortality in AML/MDS was significantly higher when compared to mortality in other HM $(p<0.0001)$ (Fig. 2).

Regarding last underlying treatments for $\mathrm{HM}$ before COVID-19, the highest mortality rate was observed among patients receiving demethylating agents (83/141, 58.9\% [95\% confidence interval $\{\mathrm{CI}\}$ 50.6-66.7]) and in palliative treatment settings (104/226, 46\% [95\%CI 39.4-52.5]). Despite the small number of patients undergoing CAR-T reinfusion, mortality rate in these patients was high (47.6\% [95\% CI 28.3-67.6]; 10/21 patients). Patients undergoing auto-HSCT or allo-HSCT had mortality rates of $27 \%$ ([95\% CI 18.2-38.1] 20/74 cases) and 24.8\% ([95\% CI 19.0-31.8] $43 / 173$ cases), respectively (Table 4$)$. The mortality rate of patients who received a transplant as most recent therapy was significantly lower when compared to non-transplant patients $(p<0.027)$ (Fig. 3).

Patients with critical COVID-19 (63.6\% [95\% CI 59.9-67.1, 438/689]) died in a higher proportion than those with severe $(30.3 \%$ [95\% CI 28.2-32.5, $526 / 1736]), p<0.0001$ or mild infection (16.7\% [95\% CI 14.1-19.8, 110/658]), $p<0.0001$. The mortality rate observed in patients with severe infection $30.3 \%$ ([95\% CI 28.2-32.5] 526/1736), was significantly higher than reported in patients with mild COVID-19 (16.7\% [95\% CI 14.1-19.8] 110/658), $p<0.0001)$. The mortality in mildly symptomatic patients was not vastly different from that observed in initially asymptomatic patients: 15.4\% ([95\% CI 12.9-18.3] 104/675) $p=0.516$ (Fig. 4, Additional file 3: Table 3). Clinical presentation with pulmonary symptoms was associated with a significantly higher mortality rate versus presentation with extrapulmonary symptomatology alone (mortality rate $876 / 2285$, $38.3 \%$ [ $95 \%$ CI $36.4-40.4$ ] vs. $163 / 742$, $22.0 \%$ [95\% CI 19.1-25.1], $p<0.0001$ ).

A higher mortality rate was reported for patients admitted to ICU (438/689, 63.5\% [95\% CI 59.9-67.1]), compared to non-ICU patients $(747 / 3112,24 \%$ [95\% CI 22.5-25.5]) $p<0.0001$. Furthermore, among the ICU patients, a significantly higher mortality rate was observed in patients with invasive MV versus those without $(322 / 449,71.7 \%$ [95\% CI 67.4-75.7] vs. 116/240, 48.3\% [95\% CI 42.1-54.6] $p<0.0001$ ).

Considering the two waves of COVID-19 $\left(1^{\text {st }}\right.$ wave March-May 2020, 2nd wave October-December 2020), there was a significant decrease in the mortality rate in the second wave $(581 / 1427,40.7 \%$ [95\% CI 38.2-43.3] vs. 439/1773, 24.8\% [95\% CI 22.8-26.8] $p<0.0001$ ) (Fig. 5). The reduction of mortality was consistent across different HM diagnoses (Fig. 6).

In the univariable Cox regression analysis, multiple factors negatively influenced mortality (Table 5). Conversely, having a neutrophil count greater than $0.5 \times 10^{9} / \mathrm{mm}^{3}$ or a lymphocyte count greater than $0.2 \times 10^{9} / \mathrm{mm}^{3}$ were found to be protective.

In the multivariable analysis the following parameters were significantly associated with higher mortality: age increase, active disease, chronic cardiopathy, liver 


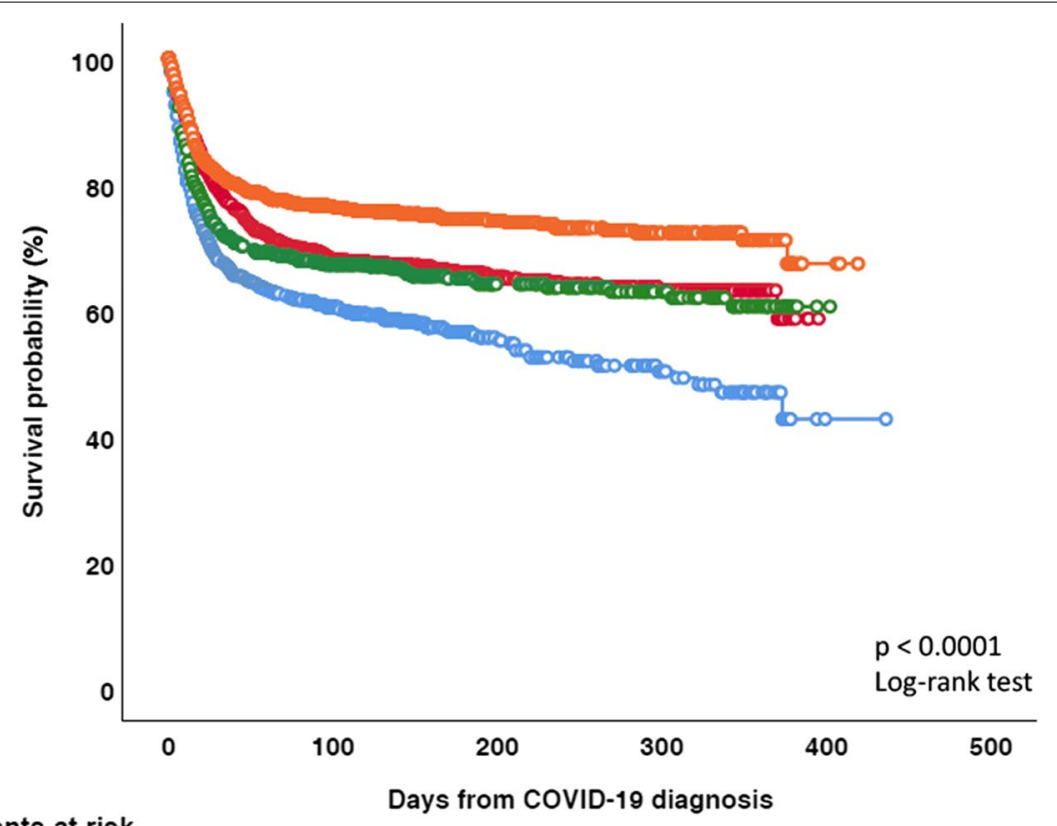

Number of patients at risk

$\begin{array}{rllllll}A M L+M D S & \mathbf{7 7 4} & 301 & 113 & 52 & 1 & 0 \\ \text { NHL } & \mathbf{1 0 8 0} & 525 & 250 & 112 & 0 & 0 \\ M M & \mathbf{6 8 2} & 304 & 130 & 73 & 1 & 0 \\ \text { Other malignancies } & \mathbf{1 2 5 4} & 625 & 299 & 136 & 3 & 0\end{array}$

AML: acute myeloid leukemia; MDS: myelodysplastic syndrome; NHL: non-Hodgkin lymphoma; MM: multiple myeloma

Fig. 2 Overall survival by the underlying disease

disease, renal impairment, smoking history, and ICU stay. Among HM, AML is the malignancy associated with a significantly high mortality (Table 5).

\section{Discussion}

The incidence of COVID-19 infection in HM ranges between 1 and 3.9\% [23]. Mostly, patients get infected in the community, although in $1.1 \%$ to $15 \%$ of infections nosocomial transmissions are reported [24]. A clear correlation between the type of HM and the incidence of COVID-19 infection has not been described in the literature, but current data indicate that lymphoproliferative disorders, in particular NHL, chronic lymphocytic leukemia, and MM are particularly associated with higher risk from COVID-19.

Here we presented a large survey on COVID-19 among HM patients, with almost 4000 patients reported from 132 hematology institutions mainly located in Europe. In addition, this survey has collected COVID-19 cases from March to December 2020, allowing us to analyze not only which patients were at risk, but also how the infectious process has evolved over time. Our data confirm that a larger number of COVID-19 cases was diagnosed among patients with lymphoproliferative disorders, in particular NHL and MM, as previously documented $[9,10]$. However, we also observed a high number of COVID-19 among patients with AML (12.5\%), which is considered a rare malignancy. As for comorbidities, our patient population reflects the overall population, with cardiovascular diseases being the most frequent comorbidity reported [16]. Most of the patients recorded in our survey had a severe/critical clinical presentation of COVID-19 (about $60 \%$ ), over two-thirds were hospitalized and about $18 \%$ required ICU admission. These data are not surprising and emphasize the frailty of HM patients, and are slightly higher compared with those reported in the literature, ranging between 15.5 to $52.4 \%$ and 6.9 to $14 \%$ for severe and critical clinical presentation, respectively [3-17].

The overall and the attributable mortality rates observed in our study (31.2\% and $22.2 \%$, respectively) are within the range of those reported in the literature among HM (published reports are summarized in Additional file 4: Table 4), confirming that COVID-19 mortality is significantly higher in HM patients than in the overall population, where current data show a mortality rate ranging between 0.1 and $9.4 \%$ across the different countries around the world (www.coronavirus.jhu.edu/data/ 


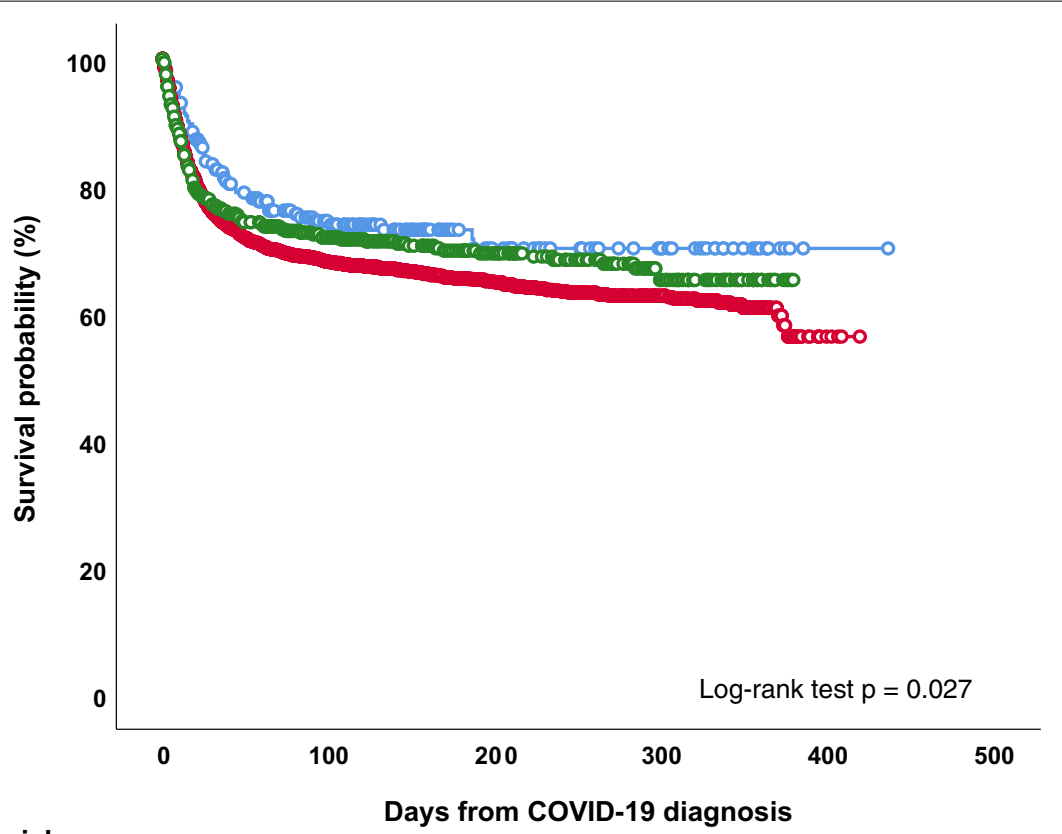

\section{Number of patients at risk}

Allogeneic/Autologous HSCT

No HSCT

No treatment
247

3008

535
125

1363

267

Days from COVID-19 diagnosis

HSCT: Hematopoietic stem-cell transplantion

Fig. 3 Overall survival by transplant vs no transplant

mortality). Moreover, as expected, the overall mortality rate has been age-dependent, with higher mortality rates observed among patients aged over 70 years. In line with other studies $[7,14,16]$, our data have shown that AML and MDS patients, especially those with high-risk MDS, have the worst clinical outcome and the highest mortality rate (up to $45 \%$ ). In fact, AML was the only that was independently associated with mortality in our multivariable model. A recently published study focusing only on AML patients reported an overall mortality very similar to that described in our study [25]. There are several possible explanations of this phenomenon. First, patients with AML/MDS are often aged over than 65 years old. Second, they present a profound immunodeficiency as a consequence of both disease and treatments received. Third, they are patients in which a treatment delay is often not possible due to the urgent need of starting an active therapy. This last aspect is quite relevant, especially if we consider that a lower mortality in patients who delayed AML treatment was described compared to those with and without treatment modification [25]. In high-risk MDS patients, treatment with demethylating agents was associated with a particularly high mortality rate. Our study highlights the role of these agents as being potentially associated with high mortality in AML/ MDS patients with COVID-19. Our data also showed that patients undergoing HSCT (either autologous or allogeneic) presented a significantly lower mortality rate following COVID-19, compared to non-transplant patients. We report an overall mortality rate of $24.8 \%$ and $27 \%$ in allo-HSCT and auto-HSCT, respectively, almost identical to that very recently described in the study of the European Society for Blood and Marrow Transplantation [12]. This observation is coherent with previous published data, suggesting a significantly lower mortality rate among transplanted patients compared with non-transplanted HM patients [15]. Patients who receive HSCT, especially an allogeneic one, are by definition younger and healthier than the overall onco-hematological patients. In fact, we observed that most of conditions associated with higher overall mortality (i.e. older age, comorbidities, uncontrolled disease) were overrepresented in the non-transplant cohort. These aspects may explain in part the lower mortality we observed in transplanted patients. Interestingly, patients undergoing CAR-T infusion have shown a worse clinical outcome in our survey, with 10 deaths among 21 COVID-19 patients registered in the database. Other significant predictors 


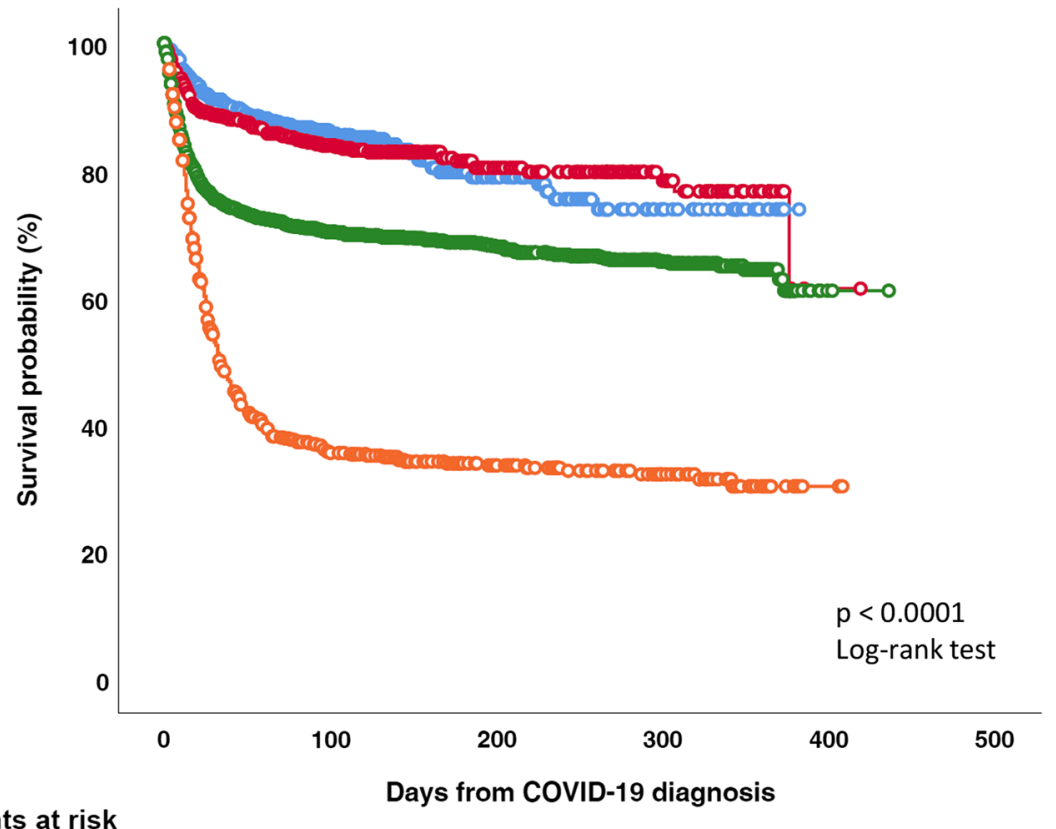

Number of patients at risk

Asymptomatic $\mathbf{6 7 2}$
Mild infection $\mathbf{6 5 8}$
Severe infection $\mathbf{1 7 3 4}$
Critical infection $\mathbf{6 8 6}$

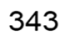

355

864

181

***, $\mathrm{p}<0.001$

Fig. 4 Overall survival by COVID-19 severity

of mortality in the multivariable analysis included active disease, chronic cardiopathy, liver disease, renal impairment, smoking history, and ICU stay.

Moreover, we found a significantly lower mortality in COVID-19 HM patients in the second wave as compared to the first wave of COVID 19. Improved clinical outcome has been documented for many different diseases, including those with the highest mortality rates. This improvement in the second wave of COVID-19 is of interest, and could be the result of several factors, including a better knowledge of the clinical course of the disease, more effective protective procedure for $\mathrm{HM}$ patients, a detection of a larger number of asymptomatic/ mild cases by screening swabs and/or an improvement of specific treatments against COVID-19, for example remdesivir, monoclonal antibodies, convalescent plasma. Coherently with our hypothesis, in the second wave, we found a significantly higher rate of asymptomatic and mild infections and a significantly lower rate of severe infections. However, even though we did not observe significant differences in HM distribution, in the second wave we found more patients with controlled disease compared to the first one.
We strongly believe that our findings will impact the management of HM patients also in the near future. Even if we are witnessing a huge worldwide vaccination program, preliminary data published so far suggest that anti-SARS-CoV-2 vaccines shows significantly less robust efficacy in eliciting an immune response in HM patients than observed in the general population [26, 27]. Moreover, we are assisting to the wide diffusion of variants of concerns under the vaccine selective pressure. Indeed, several cases of breakthrough infections have been reported in the general population, with a significant mortality rate $[28,29]$. We expect that, in the immediate future, we will assist to several cases of SARS-CoV-2 infections in fully vaccinated HM patients. From this point of view, the better understanding of epidemiologic features and risk factors for COVID-19 in HM patients, might surely help hematologists in the management of their patients and even in modifying the chemotherapeutic programs where possible. HM patients still deserve special attention and protective measures should continue.

Our large registry study comes with some limitations. First, at the time the study was designed, the role of thromboembolic phenomena of COVID-19 


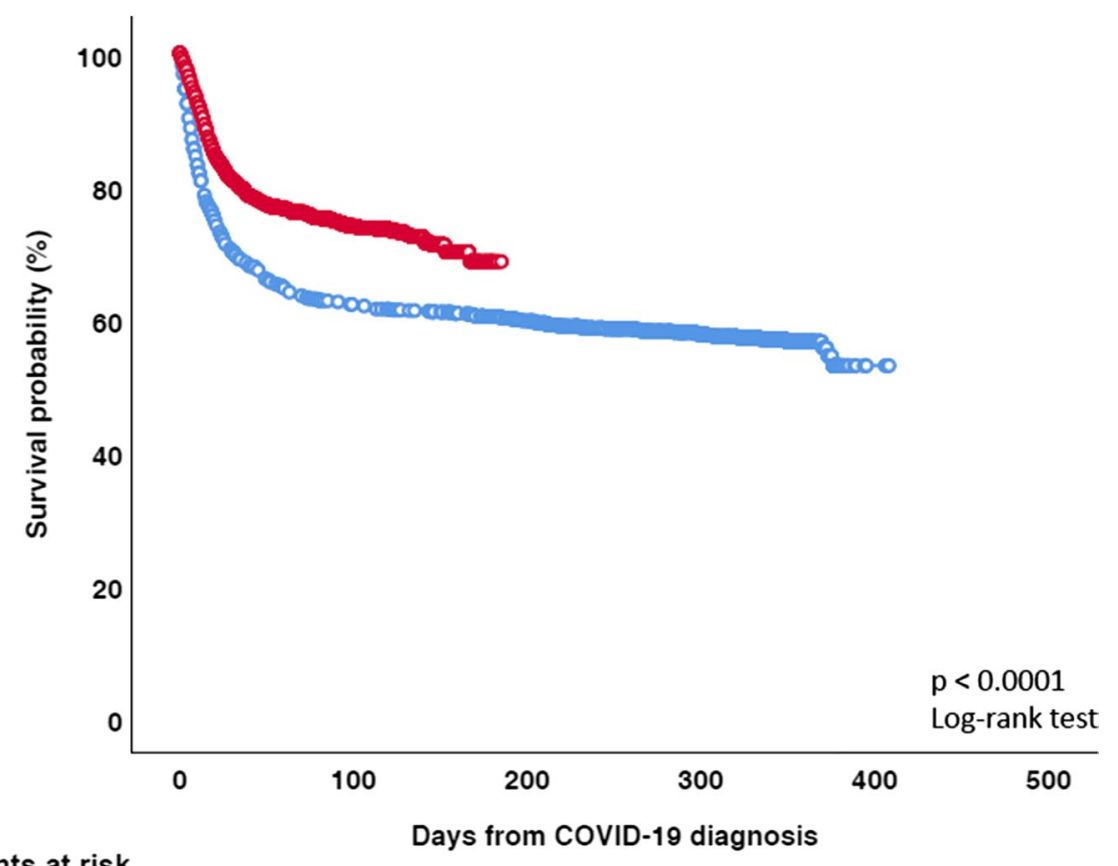

\section{Number of patients at risk}

March-May $2020 \quad 1425 \quad 798$

October-December $2020 \quad \mathbf{1 7 6 8} \quad 690$

665

0

365

2

0

Fig. 5 Overall survival by time distribution (first vs. the second wave)

\section{Overall mortality}

March - May 2020 (n=1427) October - December $2020(n=1773)$

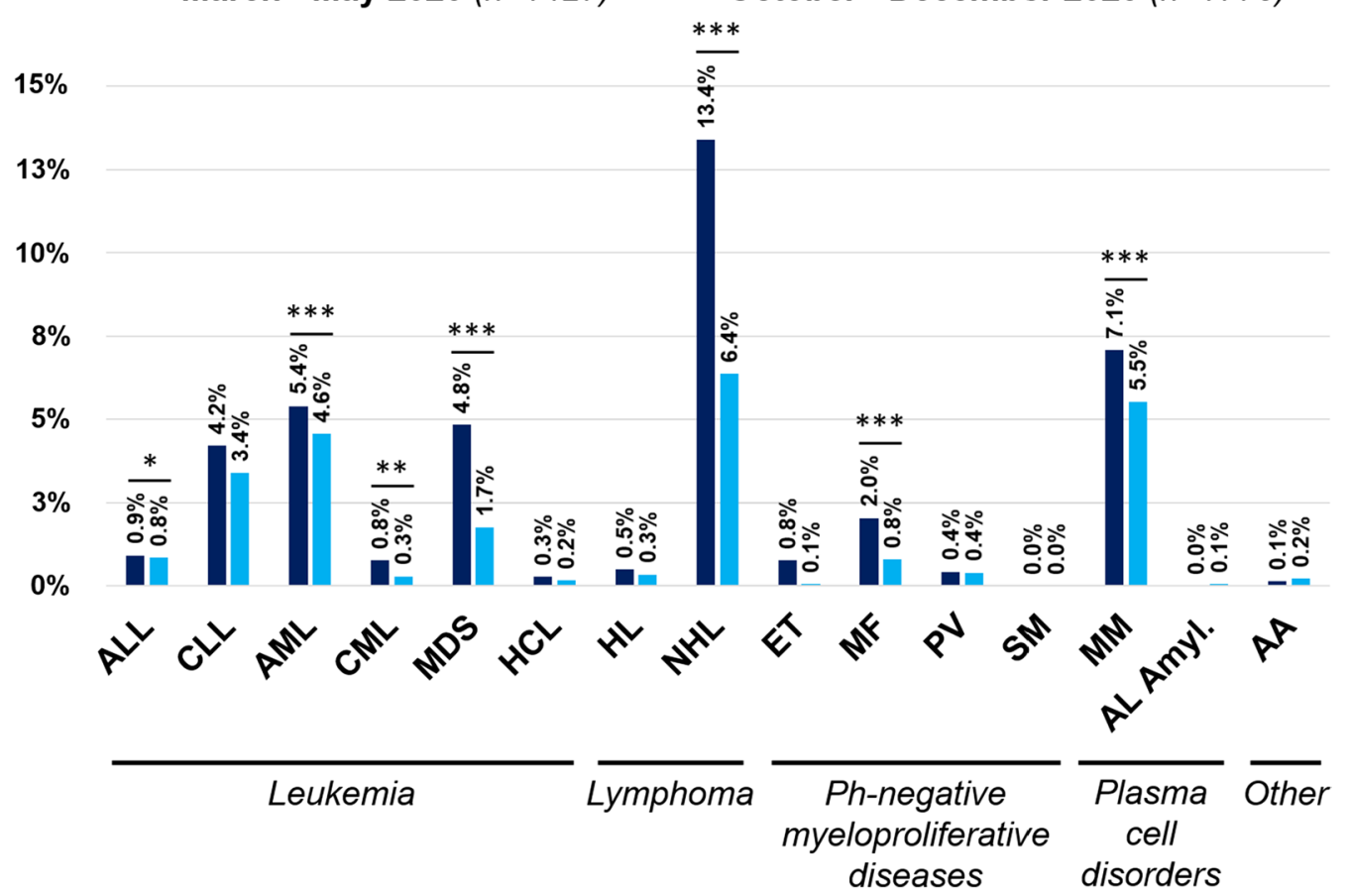

Fig. 6 Overall survival in the different HMS by time distribution (first vs. the second wave) 
Table 5 Overall mortality predictors in COVID-19 HM patients

\begin{tabular}{|c|c|c|c|c|c|c|}
\hline & \multicolumn{3}{|c|}{ Univariable } & \multicolumn{3}{|c|}{ Multivariable } \\
\hline & $p$ value & HR & $95 \% \mathrm{Cl}$ & $p$ value & HR & $95 \% \mathrm{Cl}$ \\
\hline \multicolumn{7}{|l|}{ Sex } \\
\hline Female & - & - & - & - & - & - \\
\hline Male & 0.059 & 1.119 & $0.095-1.258$ & 0.376 & 1.065 & $0.927-1.223$ \\
\hline Age & $<0.0001$ & 1.036 & $1.031-1.041$ & $<0.0001$ & 1.032 & $1.026-1.039$ \\
\hline \multicolumn{7}{|l|}{ Malignancy status } \\
\hline Controlled disease & - & - & - & - & - & - \\
\hline Active disease & $<0.0001$ & 2.107 & $1.863-2.383$ & $<0.0001$ & 1.860 & $1.615-2.141$ \\
\hline Unknown & $<0.0001$ & 2.293 & $1.607-3.274$ & $<0.0001$ & 2.353 & $1.538-3.601$ \\
\hline \multicolumn{7}{|l|}{ Hematological malignancy } \\
\hline Hodgkin lymphoma & - & - & - & - & - & - \\
\hline Chronic lymphoid leukemia & $<0.0001$ & 2.789 & $1.635-4.757$ & 0.763 & 1.093 & $0.614-1.947$ \\
\hline Acute myeloid leukemia & $<0.0001$ & 4.364 & $2.581-7.376$ & 0.011 & 2.046 & $1.176-3.557$ \\
\hline Chronic myeloid leukemia & 0.915 & 0.963 & $0.481-1.928$ & 0.086 & 0.513 & $0.239-1.099$ \\
\hline Acute lymphoblastic leukemia & 0.002 & 2.530 & $1.405-4.553$ & 0.250 & 1.457 & $0.767-2.768$ \\
\hline Non-Hodgkin lymphoma & $<0.0001$ & 3.041 & $1.814-5.100$ & 0.569 & 1.171 & $0.68-2.015$ \\
\hline Aplastic anemia & 0.040 & 2.695 & $1.045-6.948$ & 0.179 & 2.022 & $0.724-5.645$ \\
\hline Essential thrombocythemia & 0.234 & 1.585 & $0.742-3.387$ & 0.332 & 0.667 & $0.295-1.511$ \\
\hline Multiple myeloma & $<0.0001$ & 3.355 & $1.989-5.658$ & 0.630 & 1.145 & $0.661-1.984$ \\
\hline Myelodysplastic syndrome & $<0.0001$ & 4.627 & $2.704-7.919$ & 0.072 & 1.706 & $0.953-3.056$ \\
\hline Myelofibrosis & $<0.0001$ & 3.786 & $2.110-6.791$ & 0.185 & 1.540 & $0.813-2.915$ \\
\hline Polycythemia vera & 0.059 & 2.016 & $0.973-4.176$ & 0.985 & 0.992 & $0.456-2.158$ \\
\hline Amyloidosis & 0.893 & 1.150 & $0.152-8.705$ & 0.932 & - & - \\
\hline Hairy cell leukemia & 0.019 & 2.936 & $1.197-7.202$ & 0.301 & 1.806 & $0.589-5.533$ \\
\hline Systemic mastocytosis & 0.715 & 1.457 & $0.192-11.031$ & 0.968 & 0.959 & $0.126-7.323$ \\
\hline \multicolumn{7}{|l|}{ COVID-19 infection } \\
\hline Asymptomatic & - & - & - & - & - & - \\
\hline Mild infection & 0.545 & 1.087 & $0.830-1.422$ & 0.653 & 1.074 & $0.786-1.467$ \\
\hline Severe infection & $<0.0001$ & 2.127 & $1.722-2.628$ & $<0.0001$ & 1.682 & $1.312-2.157$ \\
\hline Critical infection & $<0.0001$ & 5.333 & $4.300-6.613$ & $<0.0001$ & 4.230 & $3.294-5.432$ \\
\hline Unknown & 0.623 & 1.229 & $0.540-2.800$ & 0.928 & - & - \\
\hline Chronic cardiopathy & $<0.0001$ & 2.011 & $1.792-2.257$ & $<0.0001$ & 1.406 & $1.218-1.624$ \\
\hline Liver disease & 0.008 & 1.394 & $1.091-1.781$ & 0.020 & 1.388 & $1.052-1.831$ \\
\hline Chronic pulmonary disease & $<0.0001$ & 1.516 & $1.320-1.740$ & 0.926 & 1.008 & $0.85-1.195$ \\
\hline Diabetes mellitus & $<0.0001$ & 1.352 & $1.172-1.560$ & 0.439 & 1.070 & $0.901-1.272$ \\
\hline Obesity & 0.796 & 0.974 & $0.796-1.191$ & - & - & - \\
\hline Renal impairment & $<0.0001$ & 1.883 & $1.589-2.232$ & $<0.0001$ & 1.404 & $1.143-1.724$ \\
\hline Smoking history & 0.013 & 1.224 & $1.043-1.436$ & 0.031 & 1.223 & $1.019-1.469$ \\
\hline \multicolumn{7}{|l|}{ Neutrophils, cells $/ \mathrm{mm}^{3}$} \\
\hline$\leq 0.5 \times 10^{9} / \mathrm{mm}^{3}$ & - & - & - & - & - & - \\
\hline $0.501-0.999 \times 10^{9} / \mathrm{mm}^{3}$ & $<0.0001$ & 0.594 & $0.450-0.785$ & 0.272 & 0.845 & $0.626-1.141$ \\
\hline$\geq 1 \times 10^{9} / \mathrm{mm}^{3}$ & $<0.0001$ & 0.514 & $0.431-0.614$ & 0.184 & 0.862 & $0.693-1.073$ \\
\hline \multicolumn{7}{|l|}{ Lymphocytes, cells $/ \mathrm{mm}^{3}$} \\
\hline$\leq 0.2 \times 10^{9} / \mathrm{mm}^{3}$ & - & - & - & - & - & - \\
\hline $0.201-0.499 \times 10^{9} / \mathrm{mm}^{3}$ & 0.004 & 0.746 & $0.611-0.912$ & 0.021 & 0.779 & $0.629-0.963$ \\
\hline$\geq 0.5 \times 10^{9} / \mathrm{mm}^{3}$ & $<0.0001$ & 0.499 & $0.422-0.590$ & $<0.0001$ & 0.601 & $0.499-0.722$ \\
\hline \multicolumn{7}{|l|}{ Last chemotherapy } \\
\hline >3 months before COVID-19 & - & - & - & - & - & - \\
\hline In the last 3 months & $<0.0001$ & 1.531 & $1.226-1.912$ & 0.081 & 1.236 & $0.974-1.568$ \\
\hline In the last month & $<0.0001$ & 1.688 & $1.408-2.024$ & 0.657 & 1.047 & $0.854-1.284$ \\
\hline Unknown & 0.103 & 1.578 & $0.911-2.734$ & 0.998 & 0.999 & $0.537-1.86$ \\
\hline
\end{tabular}

HR Hazard ratio, $\mathrm{Cl}$ confidence intervals 
infection was still unknown and therefore not included in the survey. Second, we have deliberately excluded the data relating to the various COVID-19 therapeutic approaches because they are extremely heterogeneous and treatment recommendations change rapidly. Third, due to our registry design we have not been able to calculate the incidence of COVID-19 in the various subclasses of HM. Last, due to the intrinsic limitations of the study, it is not possible to provide cumulative incidences regarding relevant aspects, such as mortality, as there is no certainty about whether all participating sites documented all eligible cases.

These data need to be carefully interpreted considering the incidence of individual HM in the general population and the patient performance status, which affects their social dimension and lifestyle in the community.

\section{Conclusion}

This study sheds light on the epidemiology, risk factors and outcomes of COVID-19 among patients with HM. While the introduction of COVID-19 vaccinations will lead to a marked reduction of infections in HM patients, the possibility of a lower efficacy of vaccinations needs to be taken into account [30], possibly resembling previous experiences with influenza vaccination. Future studies are needed to evaluate whether the use of vaccination will be able to prevent the development and above all mortality in the identified risk categories of HM.

\begin{abstract}
Abbreviations
allo-HSCT: Allogeneic HSCT [hematopoietic stem cell transplantation]; AML: Acute myeloid leukemia; ASH: American Society of Hematology; auto-HSCT: Autologous HSCT [hematopoietic stem cell transplantation]; BAL: Bronchoalveolar lavage; CAR-T: Chimeric antigen receptor T-cell therapies; Cl: Confidence intervals; COVID-19: Coronavirus disease 19; eCRF: Electronic case report form; EHA: European Hematology Association; EPICOVIDEHA: Epidemiology of COVID-19 Infection in Patients with Hematological Malignancies: A European Hematology Association Survey; HM: Hematological malignancy; HR: Hazard ratio; HSCT: Hematopoietic stem cell transplantation; ICU: Intensive care unit; IQR: Interquartile range; MDS: Myelodysplastic syndromes; MM: Multiple myeloma; MV: Mechanical ventilation; NHL: Non-Hodgkin lymphoma; SARSCoV-2: Severe acute respiratory syndrome coronavirus 2; TKI: Tyrosine kinase inhibitors; WHO: World Health Organization.
\end{abstract}

\section{Supplementary Information}

The online version contains supplementary material available at https://doi. org/10.1186/s13045-021-01177-0.

Additional file 1: Supplementary Table 1. Partnership from National and International Scientific Society.

Additional file 2: Supplementary Table 2. List of participating institutions.
Additional file 3: Supplementary Table 3. Demographic and clinical characteristics of enrolled patients depending on the COVID-19 severity.

Additional file 4: Supplementary Table 4. Multicentre studies on COVID-19 in patients with haematologic malignancies reported during 2020.

\section{Acknowledgements}

The authors thank all contributors for their utmost contributions and support to the project during a pandemic situation and to Susann Blossfeld and Corinna Kramer for their administrative and technical assistance.

\section{Authors' contributions}

LP served as the principal investigator. LP and JSG contributed to study design, study supervision, and data interpretation and wrote the paper. $L P$, OC, FP, PC, NK, AP, MH, PK, PC, conceived the study idea. LP, JSG, and FM did the statistical plan, analysis and interpreted the data. All the authors recruited participants and collected and interpreted data. All authors contributed to manuscript writing and review of the manuscript. All authors agreed to be accountable for all aspects of the work in ensuring that questions related to the accuracy or integrity of any part of the work are appropriately investigated and resolved. All authors read and approved the final manuscript.

\section{Funding}

EPICOVIDEHA has received funds from Optics COMMITTM (COVID-19 Unmet Medical Needs and Associated Research Extension) COVID-19 RFP program by GILEAD Science, United States (Project 2020-8223).

\section{Availability of data and materials}

Individual participant data that underlie the results reported in this Article, after de-identification (text, tables, figures, and appendices), will be available together with the study protocol. This will be from 9 to 24 months following Article publication. Data will be available only for investigators whose proposed use of the data has been approved by an independent review committee identified for this purpose.

\section{Declarations}

\section{Ethics approval and consent to participate}

The study was formally approved by the Ethical Committee of Fondazione Policlinico Universitario Agostino Gemelli-IRCCS, Università Cattolica del Sacro Cuore of Rome with the following registration number: 3226 . The study was conducted in compliance wsith Helsinki declaration and Good Clinical Practice. The corresponding local ethics committee of each participating institution has approved the EPICOVIDEHA study when applicable. EPICOVIDEHA has been registered at www.clinicaltrials.gov with the identifier NCT04733729. The anonymized data that do not contain any personally identifiable information from any sources implies that the informed consent is not applicable.

\section{Consent for publication}

Not applicable.

\section{Competing interests}

The authors declare that they have no competing interests.
Author details
${ }^{1}$ Hematology, Fondazione Policlinico Universitario Agostino Gemelli - IRCCS - Università Cattolica del Sacro Cuore, Rome, Italy. ${ }^{2}$ Università Cattolica del Sacro Cuore, Rome, Italy. ${ }^{3}$ Department I of Internal Medicine, Center for Integrated Oncology Aachen Bonn Cologne Duesseldorf, Excellence Center for Medical Mycology (ECMM), University of Cologne, Faculty of Medicine and University Hospital Cologne, Cologne, Germany. ${ }^{4}$ Cologne Excellence Cluster On Cellular Stress Responses in Aging-Associated Diseases (CECAD), University of Cologne, Faculty of Medicine and University Hospital Cologne, Cologne, Germany. ${ }^{5}$ Hematology and Stem Cell Transplant Unit, IRCCS Regina Elena National Cancer Institute, Rome, Italy. ${ }^{6}$ Stem Cell Transplant Center, AOU Citta' Della Salute E Della Scienza, Turin, Italy. ${ }^{7}$ University of Milan and Fondazione IRCCS Istituto Nazionale Dei Tumori, Milan, Italy. ${ }^{8}$ Division of Infectious Diseases and Global Public Health, 
Department of Medicine, University of California San Diego, San Diego, CA, USA. ${ }^{9}$ Clinical and Translational Fungal-Working Group, University of California San Diego, La Jolla, CA, USA. ${ }^{10}$ Section of Infectious Diseases and Tropical Medicine, Department of Internal Medicine, Medical University of Graz, Graz, Austria. ${ }^{11}$ North-Western State Medical University Named After Iliá llich Méchnikov, Saint-Petersburg, Russia. ${ }^{12}$ Department of Hematological Medicine, King's College Hospital NHS Foundation Trust, London, UK. ${ }^{13}$ Department of Medicine and Surgery, University of Insubria, ASST Sette Laghi, Ospedale Di Circolo of Varese, Varese, Italy. ${ }^{14}$ Azienda Ospedaliera San Gerardo - Monza, Monza, Italy. ${ }^{15}$ Università Milano-Bicocca, Milan, Italy. ${ }^{16}$ University Hospital Hradec Králové, Hradec Králové, Czech Republic. ${ }^{17}$ Ankara University, Ankara, Turkey. ${ }^{18}$ Policlinico Borgo Roma Verona, Verona, Italy. ${ }^{19}$ Department of Internal Medicine, Hematology and Oncology, Masaryk University and University Hospital Brno, Brno, Czech Republic. ${ }^{20}$ Fundacion Jimenez Díaz University Hospital, Health Research Institute IIS-FJD, Madrid, Spain. ${ }^{21} \mathrm{Hematology}$ and BMT Unit, Azienda Ospedaliera Nazionale SS. Antonio E Biagio E Cesare Arrigo, Alessandria, Italy. ${ }^{22} \mathrm{NIHR}$ Oxford Biomedical Research Centre, Churchill Hospital, Oxford, UK. ${ }^{23}$ Hematology and Bone Marrow Transplantation, IRCCS San Raffaele Scientific Institute, Milan, Italy. ${ }^{24}$ ASST-Spedali Civili, Brescia, Italy. ${ }^{25}$ Department of Hematology, Vall d'Hebron Hospital Universitari, Experimental Hematology, Vall d'Hebron Institute of Oncology (VHIO), Vall d'Hebron Barcelona Hospital Campus, Barcelona, Spain. ${ }^{26}$ Departament de Medicina, Universitat Autònoma de Barcelona, Bellaterra, Spain. ${ }^{27}$ Portuguese Institute of Oncology, Lisbon, Portugal. ${ }^{28}$ San Luigi Gonzaga Hospital - Orbassano, Orbassano, Italy. ${ }^{29}$ University Medical Center Groningen, Groningen, Netherlands. ${ }^{30}$ ICANS, Strasbourg, France. ${ }^{31}$ Department of Hemato-Oncology, Faculty of Medicine and Dentistry, Palacky University and University Hospital Olomouc, Olomouc, Czech Republic. ${ }^{32}$ Department of Hematology, University Hospital Dubrava, Zagreb, Croatia. ${ }^{33}$ Hospital Universitario Puerta de Hierro, Majadahonda, Spain. ${ }^{34}$ ASST Grande Ospedale Metropolitano Niguarda, Milan, Italy. ${ }^{35}$ Communicable Disease Center, Hamad Medical Corporation, Doha, Qatar. ${ }^{36}$ Fondazione IRCCS Ca'Granda Ospedale Maggiore Policlinico, Milan, Italy. ${ }^{37}$ King's College Hospital, London, UK. ${ }^{38}$ King's College London, London, UK. ${ }^{39}$ University Hospital Centre Rijeka, Rijeka, Croatia. ${ }^{40}$ Croatian Cooperative Group for Hematological Diseases (CROHEM), Zagreb, Croatia. ${ }^{41}$ Faculty of Medicine and Faculty of Health Studies, University of Rijeka, Rijeka, Croatia. ${ }^{42}$ Zealand University Hospital, Roskilde, Roskilde, Denmark. ${ }^{43}$ Clinical Microbiology and Infectious Diseases Department, Hospital General Universitario Gregorio Marañón, Madrid, Spain. ${ }^{44}$ Rigshospitalet, Copenhagen, Denmark. ${ }^{45}$ Gomel State Medical University, Gomel, Belarus. ${ }^{46}$ Institute of Hematology and Blood Transfusion, Prague, Czech Republic. ${ }^{47}$ Department of Internal Medicine, Albert Szent-Györgyi Health Center, Faculty of Medicine, University of Szeged, Szeged, Hungary. ${ }^{48}$ University Hospital Ostrava, Ostrava, Czech Republic. ${ }^{49}$ Oncology Center, Mansoura University, Mansoura, Egypt. ${ }^{50}$ Marmara University, Istanbul, Turkey. ${ }^{51} \mathrm{KU}$ Leuven, Leuven, Belgium. ${ }^{52}$ Department of Infectious Diseases, Karolinska University Hospital, Stockholm, Sweden. ${ }^{53} 3$ S-Instituto de Investigação E Inovação Em Saúde, Universidade Do Porto, Porto, Portugal. ${ }^{54}$ Cancer Drug Resistance Group, IPATIMUP-Institute of Molecular Pathology and Immunology, University of Porto, Porto, Portugal. ${ }^{55} \mathrm{Clinical}$ Hematology, Centro Hospitalar E Universitário São João, Porto, Portugal. ${ }^{56} \mathrm{Clinical}$ Hematology, Faculty of Medicine, University of Porto, Porto, Portugal. ${ }^{57} \mathrm{Hospital}$ Clinic, Barcelona, Spain. ${ }^{58}$ U.O. Ematologia E Centro Trapianti Midollo Osseo, Ospedale Maggiore, Parma, Italy. ${ }^{59}$ Fondazione IRCCS Istituto Nazionale Dei Tumori, Milan, Italy. ${ }^{60}$ Department of Biomedicine and Prevention, University of Rome Tor Vergata, Rome, Italy. ${ }^{61}$ Hematology and Transplantation, Raisa Gorbacheva Research Institute of Pediatric Oncology, Pavlov University, St. Petersburg, Russia. ${ }^{62}$ Amsterdam UMC, Location VUmc, Amsterdam, Netherlands. ${ }^{63}$ Complejo Hospitalario de Navarra, Iruña-Pamplona, Spain. ${ }^{64}$ Hospital Universitario Marqués de Valdecilla, Santander, Spain. ${ }^{65}$ La Paz University Hospital, Madrid, Spain. ${ }^{66} \mathrm{Hematology}$ Unit, Center for Translational Medicine, Azienda USL Toscana NordOvest, Livorno, Italy. ${ }^{67} \mathrm{AZ}$ Klina, Brasschaat, Belgium. ${ }^{68}$ Ematologia Con Trapianto, Ospedale Dimiccoli Barletta, Barletta, Italy. ${ }^{69} \mathrm{Clinic}$ of Hematology, University Clinical Center of Serbia, Belgrade, Serbia. ${ }^{70}$ Faculty of Medicine, University of Belgrade, Belgrade, Serbia. ${ }^{71}$ Sultan Qaboos University Hospital, Muscat, Oman. ${ }^{72} \mathrm{Hematology}$ Department, Hospital Universitario de Salamanca, Salamanca, Spain. ${ }^{73}$ IBSAL, Centro de Investigación del Cáncer-IBMCC (USAL-CSIC), Salamanca, Spain. ${ }^{74}$ Department of Haematology, Blood Neoplasms, and Bone Marrow Transplantation, Wroclaw Medical University, Wrocław, Poland. ${ }^{75} \mathrm{Cell}$ Therapy and Hematology, San Bortolo Hospital,
Vicenza, Italy. ${ }^{76}$ Department of Oncology, Hematology and Bone Marrow Transplantation With Section of Pneumology, University Medical Center Hamburg-Eppendorf, Hamburg, Germany. ${ }^{77}$ Hospital Universitario 12 de Octubre, Madrid, Spain. ${ }^{78}$ Azienda Sanitaria Universitaria del Friuli Centrale, Udine, Italy. ${ }^{79}$ Hospital Rey Juan Carlos, Móstoles, Spain. ${ }^{80}$ Division of Infectious Diseases and Hospital Epidemiology, Department of Clinical Research, University and University Hospital of Basel, Basel, Switzerland. ${ }^{81} \mathrm{Hospital}$ Escuela de Agudos Dr. Ramón Madariaga, Posadas, Argentina. ${ }^{82}$ Department of Hematology and Oncology, Medical University of Innsbruck, Innsbruck, Austria. ${ }^{83}$ University Hospital of Královské Vinohrady, Prague, Czech Republic. ${ }^{84} \mathrm{Centre}$ Hospitalier de Versailles, Versailles, France. ${ }^{85}$ Service d'Hématologie Clinique Et de Thérapie Cellulaire, Hôpital Saint Antoine, Assistance Publique-Hôpitaux de Paris, Sorbonne Université, Inserm UMRs 938, Paris, France. ${ }^{86}$ Departement d'Hematologie Clinique, CHU de Montpellier, UMR-CNRS 5535, Universite de Montpellier, Montpellier, France. ${ }^{87}$ Federal University of Rio de Janeiro, Rio de Janeiro, Brazil. ${ }^{88}$ Fundacion Jimenez Diaz University Hospital, Health Research Institute IIS-FJD, Madrid, Spain. ${ }^{89}$ National Center for Cancer Care and Research, Hamad Medical Corporation, Doha, Qatar. ${ }^{90}$ University Hospital Centre Zagreb, Zagreb, Croatia. ${ }^{91}$ Faculty of Medicine, University of Zagreb, Zagreb, Croatia. ${ }^{92}$ Hematology Service, Instituto Nacional Do Cancer, Rio de Janeiro, Brazil. ${ }^{93}$ Haematology and Haemotherapy Department, Hospital General Universitario Gregorio Marañón, Madrid, Spain. ${ }^{94}$ Scientific and Practical Center for Surgery, Transplantology and Hematology, Minsk, Belarus. ${ }^{95}$ Department of Cell Therapy and Allogenic Stem Cell Transplantation (CAST), Karolinska University Hospital, Stockholm, Sweden. ${ }^{96}$ Centro de Investigación del Cáncer-IBMCC (USAL-CSIC), Hospital Universitario de Salamanca, IBSAL, Salamanca, Spain. ${ }^{97}$ Chair Translational Research, Cologne Excellence Cluster On Cellular Stress Responses in Aging-Associated Diseases (CECAD), University of Cologne, Faculty of Medicine and University Hospital Cologne, Cologne, Germany. ${ }^{98} \mathrm{Clinical}$ Trials Centre Cologne (ZKS Köln), University of Cologne, Faculty of Medicine and University Hospital Cologne, Cologne, Germany. ${ }^{99}$ Center for Molecular Medicine Cologne (CMMC), University of Cologne, Faculty of Medicine and University Hospital Cologne, Cologne, Germany. ${ }^{100}$ German Centre for Infection Research (DZIF), Partner Site Bonn-Cologne, Cologne, Germany.

\section{Received: 9 July 2021 Accepted: 25 September 2021}

\section{Published online: 14 October 2021}

\section{References}

1. "WHO announces COVID-19 outbreak a pandemic www.euro.who.int/ en/health-topics/health-emergencies/coronavirus-covid-19/news/news/ 2020/3/who-announces-covid-19-outbreak-a-pandemic (Last access: May 31, 2021)

2. Vijenthira A, Gong IY, Fox TA, et al. Outcomes of patients with hematologic malignancies and COVID-19: a systematic review and meta-analysis of 3377 patients. Blood. 2020;136:2881-92.

3. Cattaneo C, Daffini R, Pagani C, et al. Clinical characteristics and risk factors for mortality in hematologic patients affected by COVID-19. Cancer. 2020;126:5069-76.

4. Borah P, Mirgh S, Sharma SK, et al. Effect of age, comorbidity and remission status on outcome of COVID-19 in patients with hematological malignancies. Blood Cells Mol Dis. 2021;87:102525.

5. Wood WA, Neuberg DS, Thompson JC, et al. Outcomes of patients with hematologic malignancies and COVID-19: a report from the ASH Research Collaborative Data Hub. Blood Adv. 2020;4:5966-75.

6. Kuderer NM, Choueiri TK, Shah DP, et al. Clinical impact of COVID-19 on patients with cancer (CCC19): a cohort study. Lancet. 2020;395:1907-18.

7. Lee LYW, Cazier JB, Starkey T, et al. COVID-19 prevalence and mortality in patients with cancer and the effect of primary tumour subtype and patient demographics: a prospective cohort study. Lancet Oncol. 2020;21:1309-16

8. Glenthøj A, Jakobsen LH, Sengeløv H, et al. SARS-CoV-2 infection among patients with hematological disorders: severity and one-month outcome in 66 Danish patients in a nationwide cohort study. Eur J Haematol. 2021;106:72-81.

9. Regalado-Artamendi I, Jiménez-Ubieto A, Hernández-Rivas JÁ, et al. Risk factors and mortality of COVID-19 in patients with lymphoma: a multicenter study. Hemasphere. 2021;5:e538. 
10. Chari A, Samur MK, Martinez-Lopez J, et al. Clinical features associated with COVID-19 outcome in multiple myeloma: first results from the International Myeloma Society data set. Blood. 2020;136:3033-40.

11. Sharma A, Bhatt NS, St Martin A, et al. Clinical characteristics and outcomes of COVID-19 in hematopoietic stem-cell transplantation recipients: an observational cohort study. Lancet Haematol. 2021;8:e185-93.

12. Ljungman P, de la Camara R, Mikulska M, et al. COVID-19 and stem cell transplantation; results from an EBMT and GETH multicentre prospective study. Leukemia 2021. Online ahead of print.

13. Yigenoglu TN, Ata N, Altuntas F, et al. The outcome of COVID-19 in patients with hematological malignancy. J Med Virol. 2021;93:1099-104.

14. García-Suárez J, de la Cruz J, Cedillo Á, et al. Impact of hematologic malignancy and type of cancer therapy on COVID-19 severity and mortality: lessons from a large population-based registry study. J Hematol Oncol. 2020;13:133.

15. Piñana JL, Martino R, García-García l, et al. Risk factors and outcome of COVID-19 in patients with hematological malignancies. Exp Hematol Oncol. 2020;9:21.

16. Passamonti F, Cattaneo C, Arcaini L, et al. Clinical characteristics and risk factors associated with COVID-19 severity in patients with hematological malignancies in Italy: a retrospective, multicentre, cohort study. Lancet Haematol. 2020;7:e737-45.

17. https://www.ashresearchcollaborative.org/s/covid-19-registry/datasummaries (Last access: May 25, 2021)

18. Barbui T, De Stefano V, Alvarez-Larran A, et al. Among classic myeloproliferative neoplasms, essential thrombocythemia is associated with the greatest risk of venous thromboembolism during COVID-19. Blood Cancer J. 2021;11:21.

19. Galimberti S, Petrini M, Baratè C, et al. Tyrosine kinase inhibitors play an antiviral action in patients affected by chronic myeloid leukemia: a possible model supporting their use in the fight against SARS-CoV-2. Front Oncol. 2020;10:1428.

20. Salmanton-García J, Busca A, Cornely OA, et al. EPICOVIDEHA: a ready-to use platform for epidemiological studies in hematological patients with COVID-19. Hemasphere. 2021;5(7):e612.

21. COVID-19 clinical management. Living guidance World Health Organization. January 15, 2021. WHO/2019-nCoV/Clinical/2021.1.
22. Wu Z, McGoogan JM. Characteristics of and important lessons from the coronavirus disease 2019 (COVID-19) outbreak in China: summary of a report of 72314 cases from the Chinese Center for Disease Control and Prevention. JAMA. 2020;323:1239-42.

23. Sanchez-Pina JM, Rodríguez Rodriguez M, Castro Quismondo N, et al. Clinical course and risk factors for mortality from COVID-19 in patients with hematological malignancies. Eur J Haematol. 2020;105:597-607.

24. Infante MS, González-Gascón Y, Marín I, et al. COVID-19 in patients with hematological malignancies: a retrospective case series. Int J Lab Hematol. 2020;42:e256-9.

25. Palanques-Pastor T, Megías-Vericat JE, Martínez P, et al. Characteristics, clinical outcomes, and risk factors of SARS-COV-2 infection in adult acute myeloid leukemia patients: experience of the PETHEMA group. Leuk Lymphoma 2021. https://doi.org/10.1080/10428194.2021.1948031. Online ahead of print.

26. Herishanu Y, Avivi I, Aharon A, et al. Efficacy of the BNT162b2 mRNA COVID-19 vaccine in patients with chronic lymphocytic leukemia. Blood. 2021;137:3165-73.

27. Pimpinelli F, Marchesi F, Piaggio G, et al. Fifth-week-immunogenicity and safety of anti-SARS-CoV-2 BNT162b2 vaccine in patients with multiple myeloma and myeloproliferative malignancies on active treatment: preliminary data from a single Institution. J Hematol Oncol. 2021;14:81.

28. Bergwerk M, Gonen T, Lustig Y, et al. Covid-19 Breakthrough Infections in Vaccinated Health Care Workers. N Engl J Med. 2021. https://doi.org/10. 1056/NEJMoa2109072. Online ahead of print.

29. Brown CM, Vostok J, Johnson H, et al. Outbreak of SARS-CoV-2 infections, including COVID-19 vaccine breakthrough infections, associated with large public gatherings_Barnstable County, Massachusetts, July 2021. MMWR Morb Mortal Wkly Rep. 2021;70:1059-62.

30. Terpos E, Trougakos IP, Gavriatopoulou M, et al. Low neutralizing antibody responses against SARS-CoV-2 in elderly myeloma patients after the first BNT162b2 vaccine dose. Blood. 2021;137:3674-6.

\section{Publisher's Note}

Springer Nature remains neutral with regard to jurisdictional claims in published maps and institutional affiliations.
Ready to submit your research? Choose BMC and benefit from:

- fast, convenient online submission

- thorough peer review by experienced researchers in your field

- rapid publication on acceptance

- support for research data, including large and complex data types

- gold Open Access which fosters wider collaboration and increased citations

- maximum visibility for your research: over $100 \mathrm{M}$ website views per year

At BMC, research is always in progress.

Learn more biomedcentral.com/submissions 